\title{
COFFEE IN END TIMES
}

\author{
Grounds for despair.
}

\section{BY ALVARO ZINOS-AMARO \\ \& ALEX SHVARTSMAN}

$\mathrm{H}$ enry Lindnis measured out his life with coffee spoons.

It started when Henry and his wife, Erin, watched the President deliver the news on their TV set.

Erin's hand found Henry's as they listened to the President's sombre voice. He announced that a fleet of huge alien vessels had been detected approaching the Solar System. They would arrive on Earth in four weeks. He urged everyone to remain calm.

"I'm going to make us espresso," said Henry.

Espresso was something they reserved for special occasions.

"You know, hon, I've given up coffee," Erin said, without making eye contact.

"You've what?"

"I told you I was going to. Last week. When we were having dinner with the Tillmans. Pat made a great point about how acidic it is."

Henry didn't recall the conversation. "You're worried about the health effects of coffee when we have a month left to live?"

Erin gasped. "You think it's an invasion?"

"If they meant to explore or make contact, the aliens would send a single ship. This is a war armada." He pointed at the grainy video on the screen, sent back by the probes from the far edge of the Solar System.

"Always the pessimist."

"Even if I'm wrong, things are going to get bad. People won't react well. We need to get out of the city right away. We can go to my dad's old cabin." He disengaged his hand from Erin's. Just because she chose the worst possible time to quit caffeine didn't mean he had to deprive himself. "I'm having an espresso. Then we're going to pack."

Images of the alien ships filled the screen. They were ugly things, unwieldy, grotesquely large, the size of islands, shapes with jagged metal protrusions and incomprehensible ports and turrets and antennas, like insects made of polymer and metal. Dark grey against the black of space. And they were getting closer. Every minute. Every second.
Erin went along grudgingly, complaining and calling Henry paranoid. But she helped him pack. They loaded the truck with supplies and drove to the ramshackle Northern California cabin.

He felt almost vindicated when the reports began to come in over the radio.

There were widespread riots and looting. Supermarkets and warehouses were

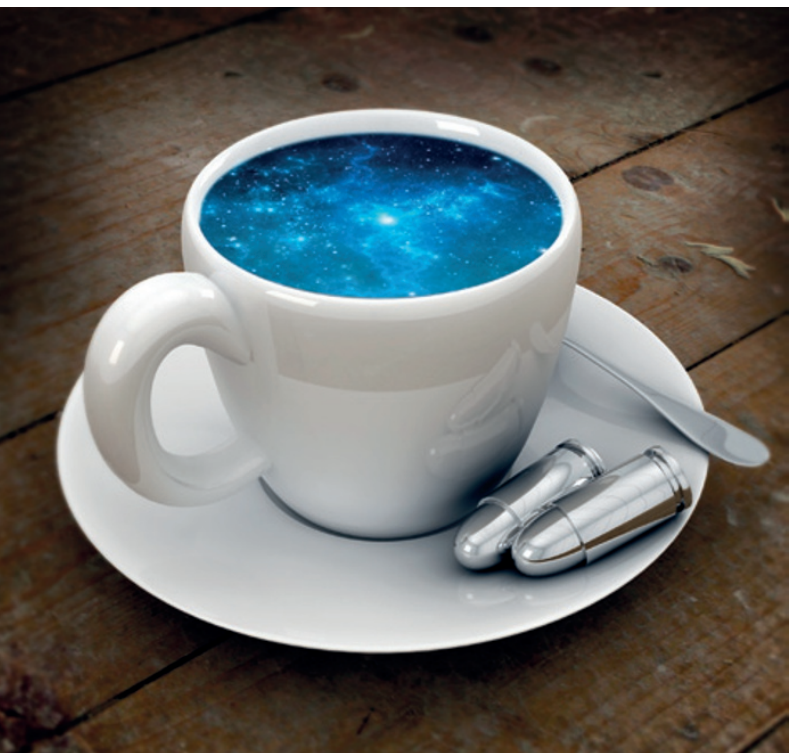

"You're trespassing," he said.

"We don't want any trouble," said the man. "We're just looking for a safe place. It's dangerous out there. Can we at least stay the night? It's getting dark."

A pair of small children, eyes wide, stared at him from the Ford's back seat.

Henry lifted his weapon. "Look somewhere else."

The intruders scrambled back into the Ford.

"I can't believe you did that," Erin called out from the doorway.

"We have limited resources, not enough to share with strangers," said Henry.

"The Henry I married would never have turned away scared children," said Erin. "You've changed."

"It's the world that's changed, Erin. You have to get used to that."

In the morning she packed a bag of clothes. "I'm driving home."

He didn't try to talk her out of it.

Henry ran out of coffee the day before the aliens were due to reach Earth. He brewed the last cup, savoured its fine aroma, and set it down on the nighttable.

Right next to the pistol.

Coffee had taught him many

cleaned out of all essentials, and people fought for whatever remained. The President declared a state of emergency and called in the army reserves. And that was only the beginning.

Henry and Erin spent three weeks in the cabin, with nothing but a few books and a radio. During the day Henry kept busy, fishing and hunting. In the evenings, they talked. Or tried to. When had their conversations become so forced?

He made himself two cups of coffee per day, rationing their last container of ground beans. It would have only been one cup per day for each of them, but Erin refused to have any.

If we can't share a cup of coffee, what can we share? Henry thought. After the first week, they hardly talked at all.

One evening, Henry heard motor sounds. He looked out the window and saw a Ford pickup pull up to the cabin. A man and a woman stepped out of the truck.

He walked out of the cabin, rifle in hand. things over the years, and even this last lesson in moderation had proved interesting.

Interesting, but ultimately pointless.

Just like everything would be in the aftermath of the alien apocalypse. With no coffee. And no Erin.

Henry exhaled loudly and let go of his memories, his sense of self, his awareness of anything except for the cup and the gun. Then he drank the warm brown liquid in short sips, and smiled.

A minute later, less than a mile away, an elk was momentarily startled at the sound of a gunshot.

The next day, the aliens arrived bearing gifts: the ability to bend space and time, groundbreaking mathematical theorems, stable cold fusion.

And a roast that was inhumanly tasty.

\section{Alvaro Zinos-Amaro and Alex}

Shvartsman are American science-

fiction writers. Learn more about them at myaineko.blogspot.com and alexshvartsman.com. 